\title{
Sorption measurements of autoclaved aerated concretes diffusion coefficient
}

\author{
Halina Garbalińska ${ }^{1, *}$, Magdalena Bochenek ${ }^{1}$ \\ ${ }^{1}$ West Pomeranian University of Technology, Faculty of Civil Engineering and Architecture, \\ al. Piastów 50, 70-311 Szczecin, Poland
}

\begin{abstract}
This study presents the results of sorption measurements and analyzes their applicability in the determination of the moisture diffusion coefficient in the porous media in which these processes occur. The test involved three classes of autoclaved aerated concrete density: 500, 600 and 700. The sorption processes under examination covered practically the whole range of hygroscopic humidity from $\mathrm{RH}=0 \%$ up to $\mathrm{RH}=98 \%$. The idea of the experiment was to place dry samples of the tested concretes to $98 \%$ relative humidity stimulated by the saturated water solution of $\mathrm{K}_{2} \mathrm{SO}_{4}$. The tests were performed until weight stabilization of all samples, which took about 10 months. On the basis of the results obtained, individual diffusion coefficients were determined using two different calculation procedures: the square root of time method and the logarithmic method. The first method applies to the initial stage of the process, while the other is used at its advanced stage. Both measurement methods were assessed in terms of their applicability and compatibility.
\end{abstract}

\section{Introduction}

The processes of moisture transport in hygroscopic capillary-porous materials are very complex and can be due to various mechanisms dependent on the moisture content [1]. At very low vapor pressures, porous materials normally do not transport moisture but only absorb water molecules on the surface of the pores. The process occurs until a thin layer of moisture covers the surface of the pores. After the absorption of the monomolecular or (at higher moisture levels) polymolecular layer of moisture, water in the gaseous phase starts to flow through the material. Although some of the smaller pores begin to be filled with water in the liquid phase, initially they are isolated. With the increasing moisture content, the flow of liquid-phase water is gradually gaining in importance as it becomes the dominant mechanism when the so-called critical humidity level is exceeded.

The moisture diffusion coefficient $D_{m}$ describes jointly all partial processes that contribute to the global flow in a variable manner, depending on the moisture concentration and the specific microstructure of the porous material.

The methods for the measurement of moisture transport coefficients within the hygroscopic humidity range can be divided into stationary and non-stationary. Nonstationary methods are based on the processes of sorption and desorption of moisture

* Corresponding author: Halina.Garbalinska@zut.edu.pl 
occurring in porous hydrophilic materials. Studies are usually carried out on samples that provide a one-dimensional moisture flow. Most often they are disc samples isolated on the side surface with a relatively small thickness to minimize the time required to reach the state of moisture equilibrium. In the analysis of the processes of sorption and desorption in works [2-6], two time intervals were selected covering respectively the initial and the advanced process phase. In both cases, the process involves various mathematical descriptions, which is the result of occurrence of different boundary conditions.

Based on measurements of kinetics of non-stationary moisture sorption and desorption processes, various researchers using different methods could determine the diffusion coefficients in building materials, e.g., in [6-17].

This article presents the results of studies over the non-stationary processes of sorption of autoclaved aerated concretes of three density classes - 500, 600 and 700 - carried out in the framework of the research paper [18]. Provided with data on the kinetics of these processes, the moisture diffusion coefficients of the tested concretes were determined using two calculation methods: the square root of time method and the logarithmic method.

\section{Methodology used to determine diffusion coefficient}

In work [19] the methods for the determination of the diffusion coefficient $D_{m}$ were described in detail for the initial and the advanced stage of the sorption and desorption process. For the initial phase of the process, the $\sqrt{ } t$ method was proposed according to which the diffusion coefficient can be determined from the initial slope of the mass change curve $\Delta m_{t}$ as a function of square root of time $\sqrt{ } t$. Conceptual scheme is shown in Figure 1.

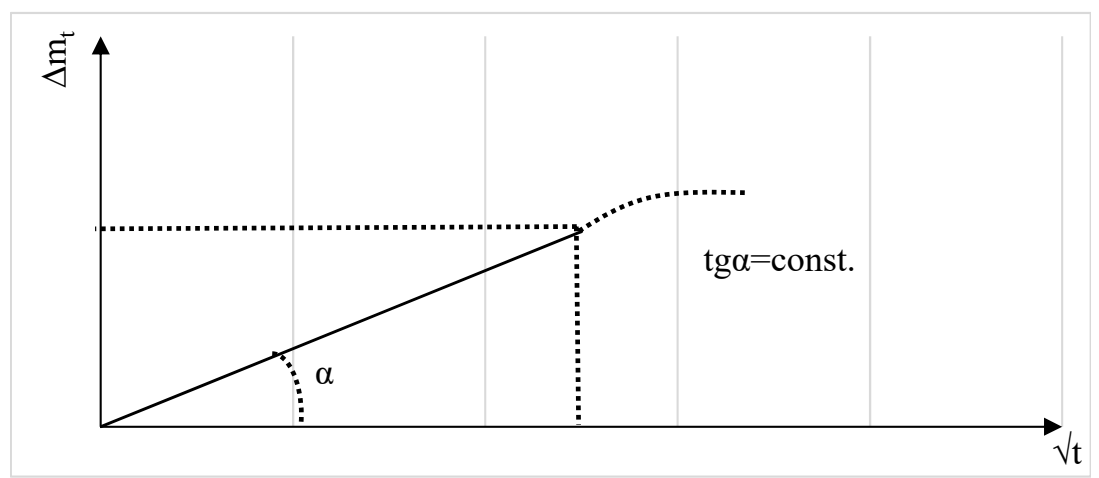

Fig. 1. Changes in sample mass $\Delta m_{t}$ in the process of sorption in relation to $\sqrt{ } t$, [19].

Knowing the angle of slope of the rectilinear section on the graph $\Delta m_{t}=\mathrm{f}(\sqrt{ } t)$, it is possible to determine the diffusion coefficient $D_{m}$ according to the following formula:

$$
D_{m}=a_{\sqrt{t}}^{2} \frac{\pi}{16 A^{2} \Delta c_{m}^{2}}
$$

where:

$$
a_{\sqrt{t}}=\frac{\Delta m_{t}}{\sqrt{t}}
$$

The formula (1) can be transformed into (3), which is more practical in application: 


$$
D_{m}=a_{\sqrt{t}}^{2} \frac{\pi d^{2}}{16 \Delta m_{\max }^{2}}
$$

On the other hand, the method for the advanced stage of the process proposed in [19] was based on the logarithmic principle according to which the diffusion coefficient can be determined from the slope of the rectilinear section of the curve $\ln \left(1-\Delta m_{t} / \Delta m_{\max }\right)$ as a function of time $t$. Conceptual scheme is shown in Figure 2.

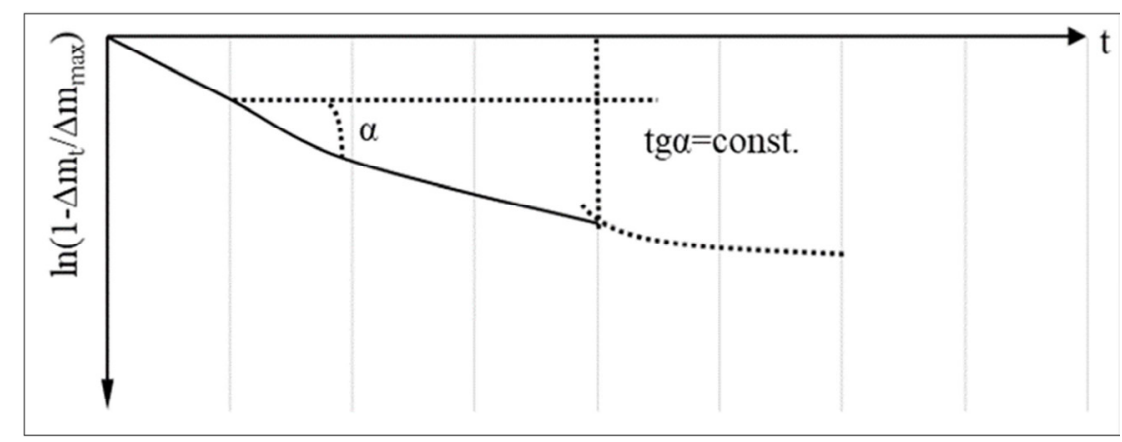

Fig. 2. The function variation curve $\ln \left(1-\Delta m_{t} / \Delta m_{\max }\right)=f(t),[19]$.

Knowing the slope $a_{l n}$ of the rectilinear section, the diffusion coefficient $D_{m}$ can be calculated according to the following formula:

$$
D_{m}=-a_{l n} \frac{d^{2}}{\pi^{2}}
$$

where:

$$
a_{l n}=\frac{\ln \left(1-\frac{\Delta m_{t}}{\Delta m_{\max }}\right)+0.21}{t}
$$

\section{Sorption measurements}

This article presents an examination of autoclaved aerated concrete with density classes 500,600 and 700. Sorption measurements were carried out on samples with surface area of $6 \times 12 \mathrm{~cm}$ and thickness of approx. $1 \mathrm{~cm} .34$ samples from each class of concrete were prepared.

First, the samples were inventoried in terms of geometric dimensions and then dried to constant weight at $105^{\circ} \mathrm{C}$ using a laboratory drier. After drying, the samples were weighed using scales with accuracy of \pm 0.001 gram, then insulated on the side surfaces and again dried at $105^{\circ} \mathrm{C}$ to constant weight.

The samples were placed on stands in specially prepared sealed containers at the bottom of which saturated aqueous solutions of $\mathrm{LiCl}, \mathrm{MgCl}_{2}, \mathrm{Mg}\left(\mathrm{NO}_{3}\right)_{2}, \mathrm{NaNO}_{2}, \mathrm{NaCl}, \mathrm{KCl}$ and $\mathrm{K}_{2} \mathrm{SO}_{4}$ salts were located. The relative humidity values above the saturated salt solutions in the equilibrium state were established on the basis of [20-23].

Measurements of sorption consisted in recording the changes in the weight of the samples. The sorption processes were initiated by exposing dry samples to air of different humidity levels. The samples were stored at $20^{\circ} \mathrm{C}$ and exposed to humidity according to the following pattern: $0 \rightarrow 11 \%, 0 \rightarrow 33 \%, 0 \rightarrow 54 \%, 0 \rightarrow 65 \%, 0 \rightarrow 75 \%, 0 \rightarrow 85 \%, 0 \rightarrow 98 \%$. 
Initially, measurements were performed every 6 hours, then every 12 hours. After the sorption process had slowed down, the samples were being weighed every 48 hours, gradually increasing the intervals between the measurements. The entire experiment lasted a total of 10 months.

Figure 3 shows graphs of the sorption kinetics for the widest range of all studied humidity levels $\varphi=0 \rightarrow 98 \%$. The figures 3a), 3b) and 3c) include kinetics curves designated for four samples of each class tested for about 7,000 hours in the assumed climatic conditions.

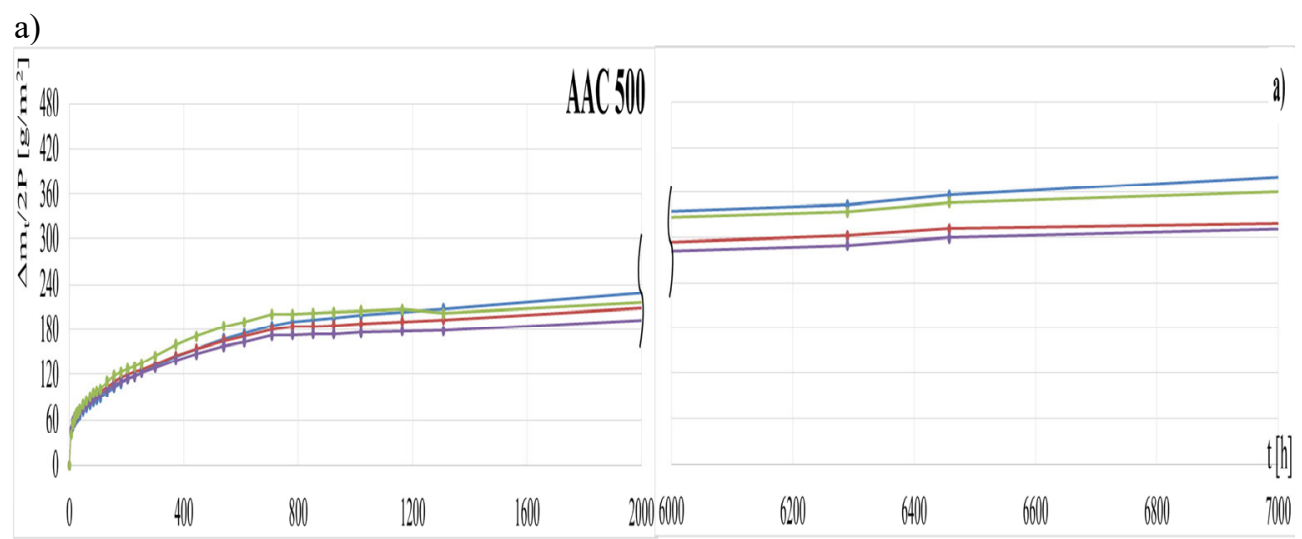

b)

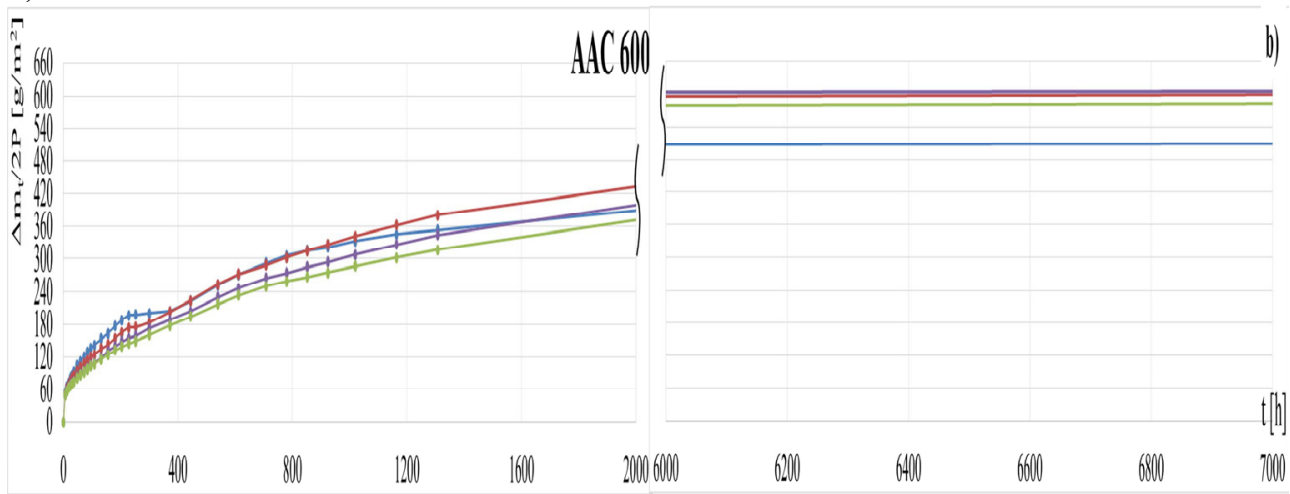

c)

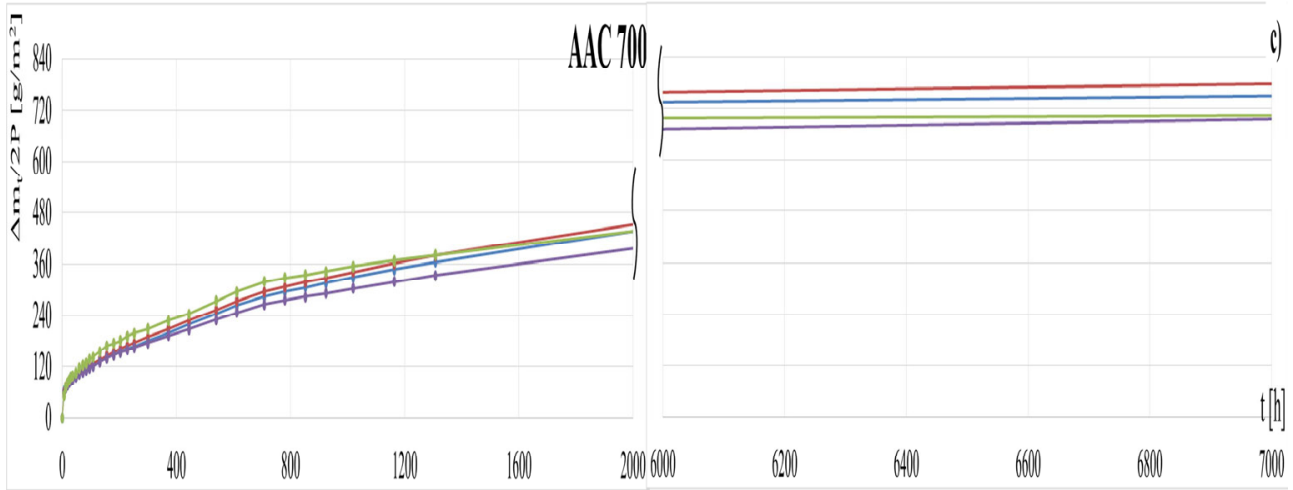

Fig. 3. Kinetics sorption curves $\Delta m_{t} / 2 P=\mathrm{f}(t)$ designated for: a) AAC500, b) AAC600, c) AAC700. 


\section{Results}

\subsection{Determination of the diffusion coefficient using the $\sqrt{ } t$ procedure}

The first step was to determine the moisture diffusion coefficients using the $\downarrow_{t}$ method. For this end, mass changes in the square root of time function were represented in graphs and sections of rectilinear course were assigned.

The selected sections of rectilinear function behavior $\Delta m_{t}=\mathrm{f}(\sqrt{ } t)$ are shown in figures 4, 5,6 presenting the results obtained for individual samples of the examined density classes: 500,600 and $700 \mathrm{~kg} / \mathrm{m}^{3}$.

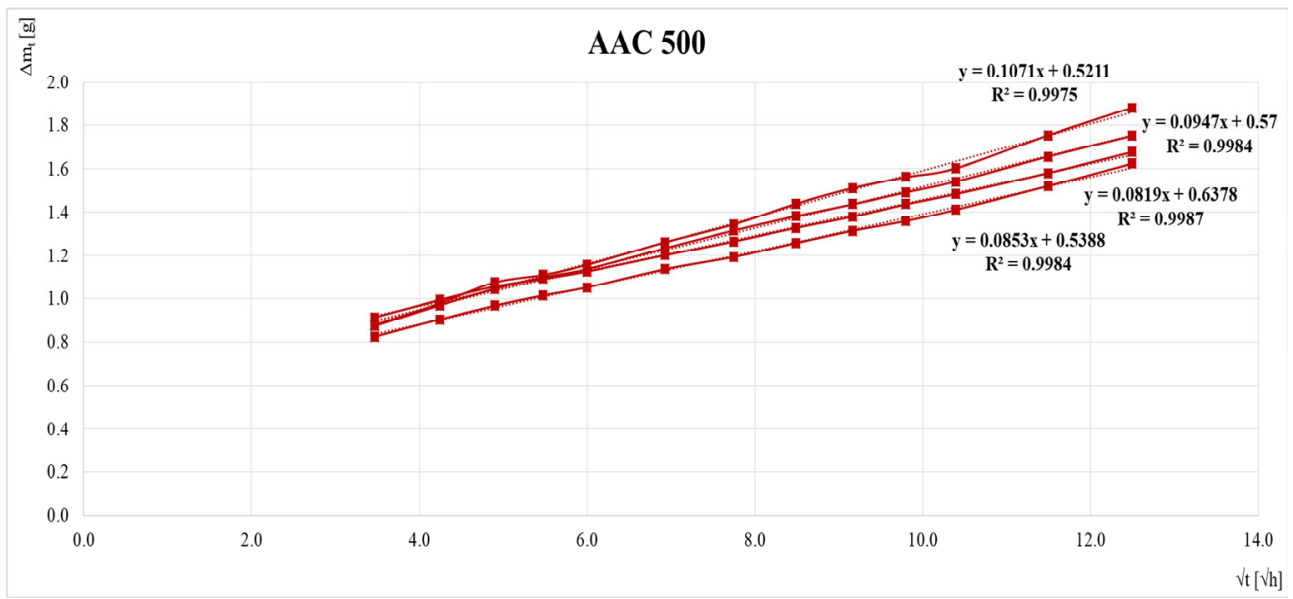

Fig. 4. Assigned sections of rectilinear course of the $\Delta m_{t}=\mathrm{f}(\sqrt{ } t)$ dependency reconstructed for class 500 samples examined in the sorption process at $T=20^{\circ} \mathrm{C}$ and $\varphi=0 \rightarrow 98 \%$.

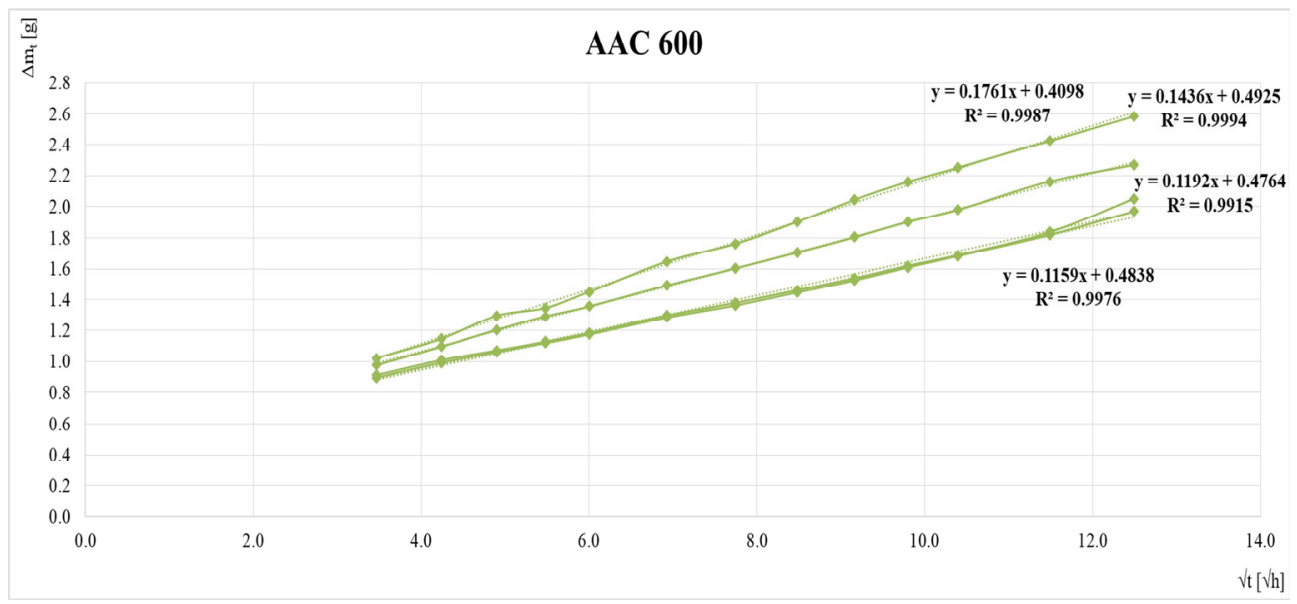

Fig. 5. Assigned sections of rectilinear course of the $\Delta m_{t}=\mathrm{f}(\sqrt{ } t)$ dependency reconstructed for class 600 samples examined in the sorption process at $T=20^{\circ} \mathrm{C}$ and $\varphi=0 \rightarrow 98 \%$. 


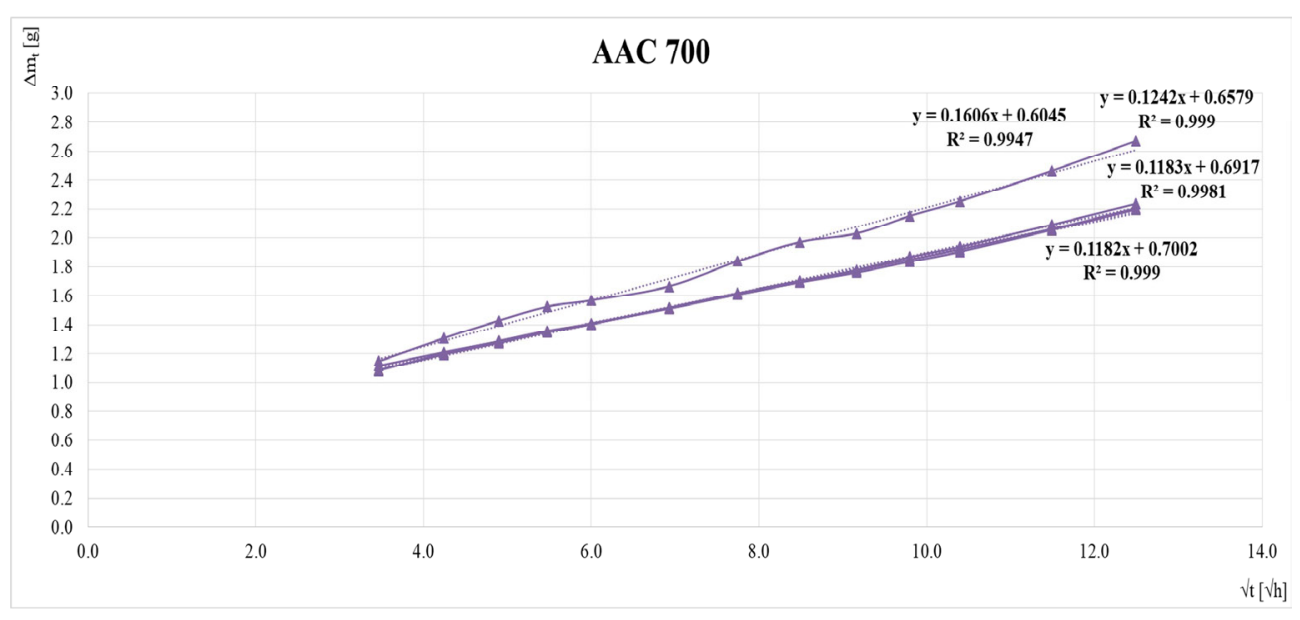

Fig. 6. Assigned sections of rectilinear course of the $\Delta m_{t}=f(\sqrt{ } t)$ dependency reconstructed for class 700 samples examined in the sorption process at $T=20^{\circ} \mathrm{C}$ and $\varphi=0 \rightarrow 98 \%$.

Table 1 shows the singular average values of moisture diffusion coefficients for the analyzed classes of autoclaved aerated concrete determined for the sorption process using the $\sqrt{ } t$ method.

Table 1. The singular results and average values of the moisture diffusion coefficients $D_{m}\left[\mathrm{~m}^{2} / \mathrm{s}\right]$, determined from the sorption process using the $\sqrt{t}$ method.

\begin{tabular}{|c|c|c|c|c|}
\hline$\varphi(\%)$ & Sample & AAC 500 & AAC 600 & AAC 700 \\
\hline $0-98$ & Sample 1 & $1.70 \cdot 10^{-12}$ & $3.91 \cdot 10^{-12}$ & $0.92 \cdot 10^{-12}$ \\
\hline $0-98$ & Sample 2 & $2.94 \cdot 10^{-12}$ & $1.89 \cdot 10^{-12}$ & $0.96 \cdot 10^{-12}$ \\
\hline $0-98$ & Sample 3 & $2.47 \cdot 10^{-12}$ & $1.55 \cdot 10^{-12}$ & $1.04 \cdot 10^{-12}$ \\
\hline $0-98$ & Sample 4 & $2.93 \cdot 10^{-12}$ & $1.34 \cdot 10^{-12}$ & $1.95 \cdot 10^{-12}$ \\
\hline $0-98$ & Average & $\mathbf{2 . 5 1 \cdot \mathbf { 1 0 } ^ { - 1 2 }}$ & $\mathbf{2 . 1 7 \cdot \mathbf { 1 0 } ^ { - 1 2 }}$ & $\mathbf{1 . 2 2} \cdot \mathbf{1 0}^{-12}$ \\
\hline
\end{tabular}

\subsection{Determination of diffusion coefficient using the logarithmic procedure}

The second step was to determine the diffusion coefficients $D_{m}$ using the logarithmic method. With this aim, graphs of changes as a function of time $\ln \left(1-\Delta m_{t} / \Delta m_{\max }\right)$ were drawn up and sections of rectilinear course were determined of which values of the coefficient $a_{l n}$ were read off. The assigned sections of rectilinear function behavior $\ln \left(1-\Delta m_{t} / \Delta m_{\max }\right)=\mathrm{f}(t)$ are shown in figures $7,8,9$ presenting the results obtained for individual samples of the examined density classes: 500,600 and $700 \mathrm{~kg} / \mathrm{m}^{3}$. 


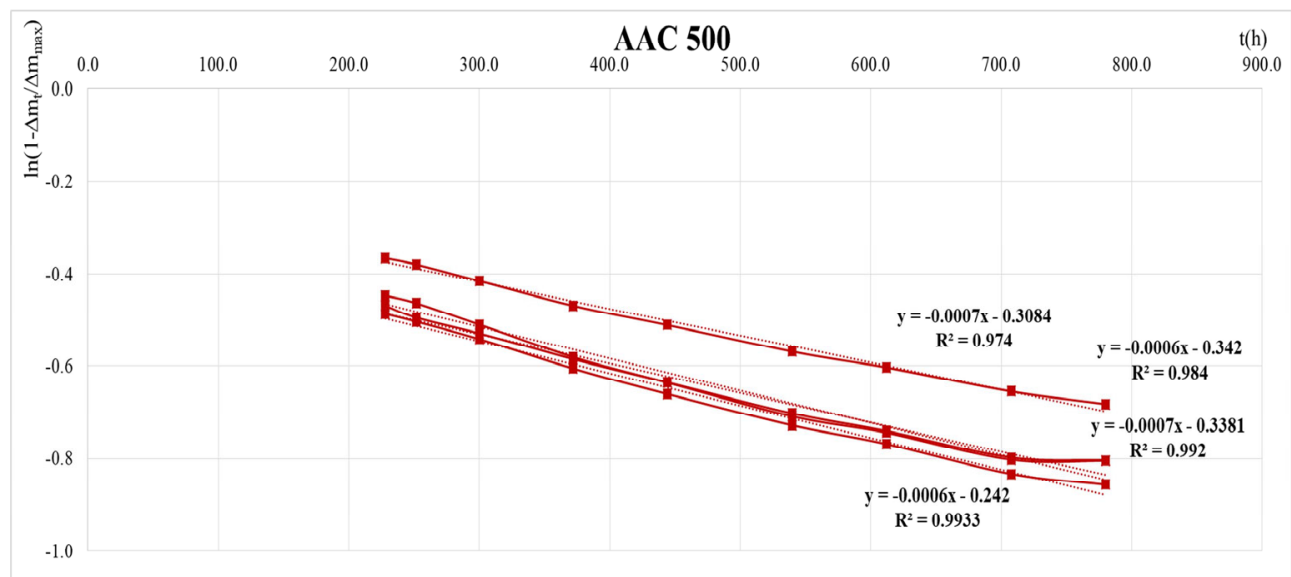

Fig. 7. Assigned sections of rectilinear course of the dependency $\ln \left(1-\Delta m_{t} / \Delta m_{\max }\right)=f(t)$ represented for class 500 samples examined in the process of sorption at $T=20^{\circ} \mathrm{C}$ and $\varphi=0 \rightarrow 98 \%$.

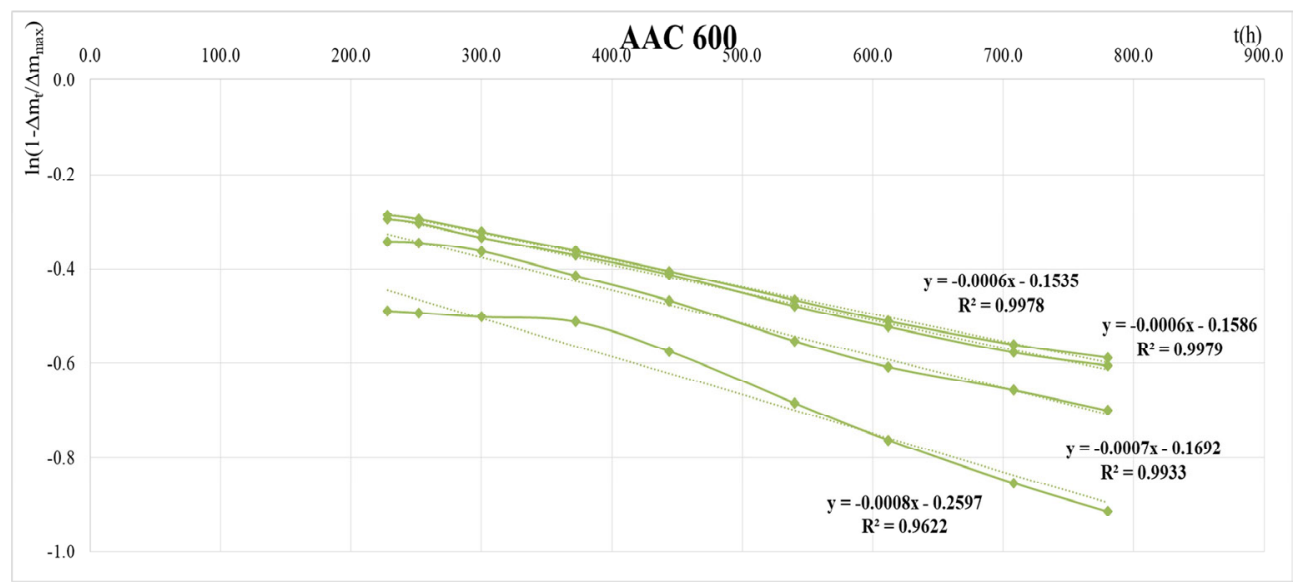

Fig. 8. Assigned sections of rectilinear course of the dependency $\ln \left(1-\Delta m_{t} / \Delta m_{\max }\right)=f(t)$ represented for class 600 samples examined in the process of sorption at $T=20^{\circ} \mathrm{C}$ and $\varphi=0 \rightarrow 98 \%$.

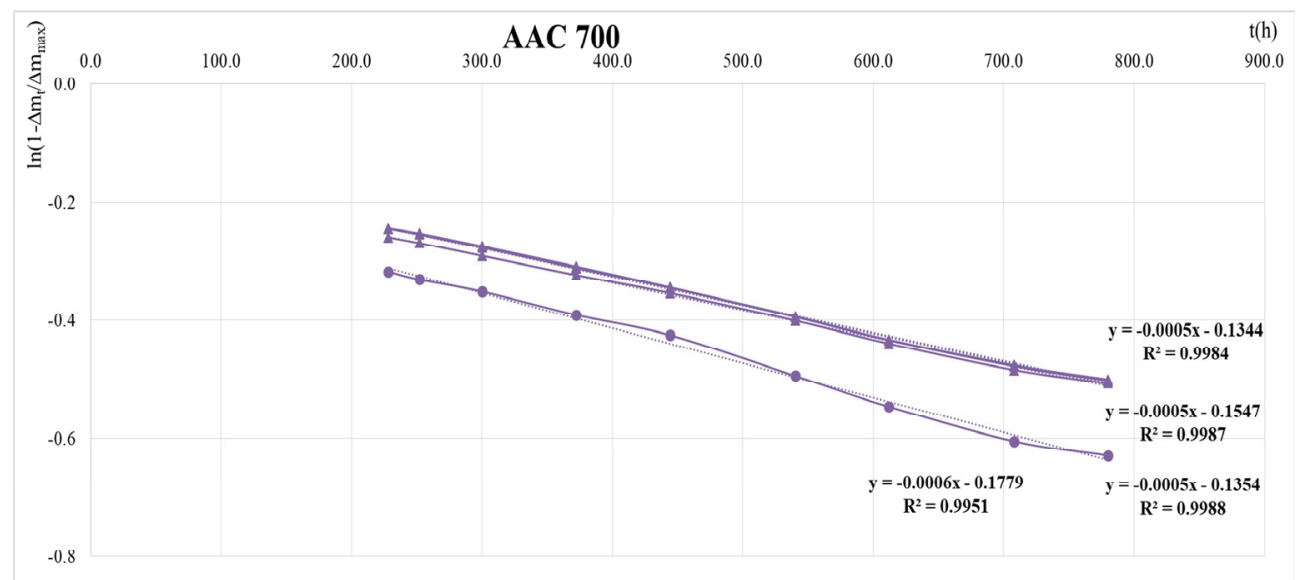

Fig. 9. Assigned sections of rectilinear course of the dependency $\ln \left(1-\Delta m_{t} / \Delta m_{\max }\right)=f(t)$ represented for class 700 samples examined in the process of sorption at $T=20^{\circ} \mathrm{C}$ and $\varphi=0 \rightarrow 98 \%$. 
Table 2 lists the particular and average values of the moisture diffusion coefficients for the analyzed classes of autoclaved aerated concrete determined for the sorption process using the logarithmic method.

Table 2. The particular results and average values of the moisture diffusion coefficients $D_{m}\left[\mathrm{~m}^{2} / \mathrm{s}\right]$, determined for the sorption process using the logarithmic method.

\begin{tabular}{|c|c|c|c|c|}
\hline$\varphi(\%)$ & Sample & AAC 500 & AAC 600 & AAC 700 \\
\hline $0-98$ & Sample 1 & $2.37 \cdot 10^{-12}$ & $3.35 \cdot 10^{-12}$ & $2.07 \cdot 10^{-12}$ \\
\hline $0-98$ & Sample 2 & $2.76 \cdot 10^{-12}$ & $2.79 \cdot 10^{-12}$ & $2.02 \cdot 10^{-12}$ \\
\hline $0-98$ & Sample 3 & $2.65 \cdot 10^{-12}$ & $2.52 \cdot 10^{-12}$ & $1.88 \cdot 10^{-12}$ \\
\hline $0-98$ & Sample 4 & $2.64 \cdot 10^{-12}$ & $2.29 \cdot 10^{-12}$ & $2.47 \cdot 10^{-12}$ \\
\hline $0-98$ & Average & $\mathbf{2 . 6 0} \cdot \mathbf{1 0}^{-12}$ & $\mathbf{2 . 7 4} \cdot \mathbf{1 0}^{-12}$ & $\mathbf{2 . 1 1} \cdot \mathbf{1 0}^{-12}$ \\
\hline
\end{tabular}

\section{Conclusions}

The results of non-stationary sorption measurements obtained in the framework of [18] have shown that both the $V_{t}$ procedure as well as the logarithmic procedure allowed for the determination of unambiguous values of diffusion coefficients $D_{m}$ in terms of the widest range of humidity, i.e. $0-98 \%$.

In order to show the relationships between the mean diffusion coefficients of individual classes, an overview was drawn up, shown in Figure 10.

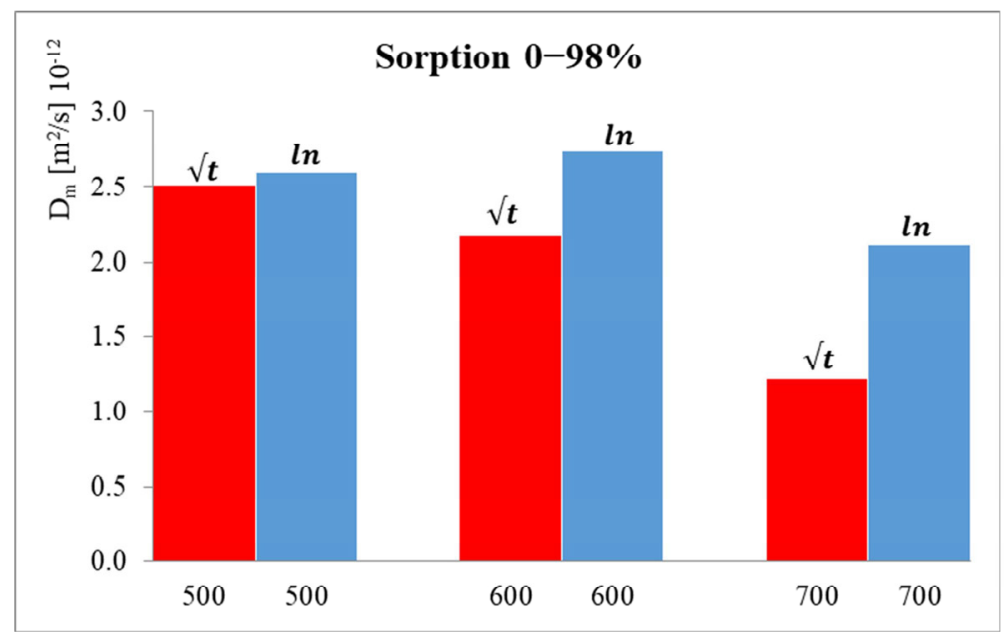

Fig. 10. The relationships between the mean diffusion coefficients of individual classes.

Diffusion coefficients determined using both methods show the lowest differences in AAC500, higher differences in AAC600 and the largest differences in the case of AAC700. A homogenous trend in each density class was observed - the $\sqrt{ } t$ method always provides lower values of the diffusion coefficient compared to the logarithmic method.

The results show that the extent of discrepancies grows with the increasing material density. The ratio $D_{m}(\ln ) / D_{m}(\sqrt{ } t)$ is 1.04 for AAC500, $D_{m}(\ln ) / D_{m}(\sqrt{ } t)$ reaches 1.26 for AAC600 and equals to 1.73 for AAC700.

Therefore, it can be assumed that with lesser density autoclaved aerated concretes (AAC500, AAC600) there is possibility of interchangeable use of both the $V_{t}$ procedure and the logarithmic method. In such a case, the discrepancies should not exceed $30 \%$ which is 
acceptable in terms of humidity measurements - which are difficult to attain, especially at high humidity. In the case AAC700, however, the extent of discrepancies in $D_{m}(\sqrt{ } t)$ and $D_{m}(\ln )$ excludes using both methods interchangeably.

A comparative analysis of individual classes should be based on the $\sqrt{ } t$ procedure which is characterized by higher precision, given the fact that it allows to cover a greater number of measurement points. Comparing the coefficients determined by means of this method, we find a significant effect of the structure within the same material group. In summary, the 700 $\mathrm{AAC}$ is characterized by the lowest diffusion coefficient while the $500 \mathrm{AAC}$ has the highest value of diffusion coefficient. Coefficients $D_{m}(\sqrt{ } t)$ are in the following mutual proportions: $D_{m, 500}(\sqrt{ } t) / D_{m, 600}(\sqrt{ } t)=2.51 / 2.17=1.16, \quad D_{m, 600}(\sqrt{ } t) / D_{m, 700}(\sqrt{ } t)=2.17 / 1.22=1.78$, $D_{m, 500}(\sqrt{ } t) / D_{m, 700}(\sqrt{ } t)=2.51 / 1.22=2.06$. Therefore, the increasing density of AAC involves a significant reduction of values of parameters describing the processes of moisture transportation within the partition wall. It seems to be crucial to select proper types of porous concrete for particular applications, having in mind potential moisture conditions.

\section{References}

1. W. M. Willems, Lehrbuch der Bauphysik (Springer-Vieweg, 2013)

2. J. Crank, The Mathematics of Diffusion (Oxford Science Publications, 1989)

3. H. Garbalińska, International Journal of Heat and Mass Transfer, 45, 1353-1357 (2002)

4. H. Garbalińska, Cement and Concrete Research, 36, 1294-1303 (2006)

5. H. Garbalińska, Heat and Mass Transfer, 40, 963-972 (2004)

6. B. Majkowski, H. Garbalińska, Inżynieria i Budownictwo, 9, 499-501 (2017)

7. A. Anderberg, L. Wadsö, Cement and Concrete Research, 38, 89-94 (2008)

8. A. K. Apeagyei, J.R.A. Grenfell, G.D. Airey, Journal of Materials in Civil Engineering, 26, 8, 1-12 (2014)

9. J. Arfvidsson, M. J. Cunningham, Building and Environment, 35, 239-249, (2000)

10. E. Bagda, Farbe und Lack, 94, 4, 270-271 (1988)

11. V. Baroghel-Bouny, Cement and Concrete Research, 37, 438-454 (2007)

12. J. M. P. Q. Delgado, N. M. M Ramos, V. P. de Freitas, Heat and Mass Transfer, 47, 1491-1498 (2011)

13. J. M. P. Q. Delgado, N. M. M Ramos, V. P. de Freitas, Journal of Building Physics, 35, 3, 251-266 (2011)

14. H. M. Künzel K. Kiessl, Bauphysik, 12, 5, 140-144 (1990)

15. H. Garbalińska, S.J. Kowalski, M. Staszak, Cement and Concrete Research, 40, 752-762 (2010)

16. H. Garbalińska, S.J. Kowalski, M. Staszak, Transport in Porous Media, 85, 79-96 (2010)

17. H. Garbalińska, S.J. Kowalski, M. Staszak, International Journal of Heat and Mass Transfer, 56, 212-222 (2013)

18. M. Bochenek, PHD Thesis, 2016

19. H. Garbalińska, Izotermiczne wspótczynniki transportu wilgoci porowatego materiału budowlanego (Wydawnictwo Politechniki Szczecińskiej 2002)

20. ASTM E104-02, West Conshohocken, PA, ASTM International (2012)

21. L. Greenspan, Journal of Research of the National Bureau of Standards - A. Physics and Chemistry, 81 A, 1 (1977)

22. M. Jiřiccková, R. Černý, P. Rovnaniková, Acta Polytechnica, 43, 2, 39-43 (2003)

23. PN-EN ISO 12571:2013, Polski Komitet Normalizacyjny, Warszawa (2013) 